Article

\title{
Identification of Three Dalbergia Species Based on Differences in Extractive Components
}

\author{
Xiaoqian Yin ${ }^{1}$, Anmin Huang ${ }^{1, *(\mathbb{D})}$, Shifeng Zhang ${ }^{2}, \mathrm{Ru}_{\mathrm{Liu}}{ }^{1}$ (i) and Fang Ma ${ }^{3}$ \\ 1 Research Institute of Wood Industry, Chinese Academy of Forestry, Beijing 100091, China; \\ yxqwzy@163.com (X.Y.); liuru@criwi.org.cn (R.L.) \\ 2 Beijing Key Laboratory of Wood Science and Engineering, Beijing Forestry University, Beijing 100083, China; \\ shifeng.zhang@bjfu.edu.cn \\ 3 Department of Chemistry, Tsinghua University, Beijing 100084, China; mf690772309@163.com \\ * Correspondence: hbham2000@sina.com; Tel.: +86-10-6288-9437
}

Received: 3 August 2018; Accepted: 24 August 2018; Published: 28 August 2018

\begin{abstract}
Dalbergia cultrate, Dalbergia latifolia, and Dalbergia melanoxylon are precious and valuable traded timber species of the genus Dalbergia. For chemotaxonomical discrimination between these easily confused species, the total extractive content of the three wood species was determined using four different organic solvents. Fourier transform infrared (FTIR) spectroscopy was used to analyze functional group differences in the extractive components, inferring the types of principal chemical components according to characteristic peak positions, intensities, and shapes. Gas chromatography-mass spectrometry (GC-MS) was carried out a detailed characterization of the extractive components. The relative content of individual chemical components was determined by area normalization. Results revealed differences in the chemical components and total and individual extract contents of the three Dalbergia species, indicating that FTIR and GC-MS spectroscopy can be applied to identify and discriminate between Dalbergia cultrate, Dalbergia latifolia, and Dalbergia melanoxylon.
\end{abstract}

Keywords: Dalbergia spp.; distinction; extractives; FTIR; GC-MS

\section{Introduction}

Wood extractives are non-structural wood molecules that represent a minor fraction in wood, specifically defined as compounds that can be extracted by polar, non-polar, or neutral solvents $[1,2]$. Wood extractives account for approximately $2 \%$ to $5 \%$ of wood content, however, relatively high amounts of extractives can be found in some tropical woods, especially chemical extractives that are highly concentrated in heartwood [3-5]. Studies have demonstrated that many extractive components exhibit various biological activities and are important in medical applications [6,7]. Wood extractives include an array of compounds, usually aliphatic, terpenoid and phenolic in nature. According to the literature [8], Dalbergia spp. are rich in aromatic compounds, however, significant differences have been found in the types and contents of wood extractives, even within the same genus [3].

Dalbergia is a genus of trees belonging to the Fabaceae (pea) family, that includes approximately 250 species. All species of Dalbergia spp. were listed in the 17th Convention on International Trade in Endangered Species of Wild Fauna and Flora [9]. Dalbergia cultrate (Benth.), Dalbergia latifolia (Roxb.), and Dalbergia melanoxylon (Guill. \& Perr.) are high-profile species renowned for their use in high-quality products worldwide [10,11]. These species are used in luxury furniture, artwork, and musical instruments due to their refined colors and excellent hardness and intensity properties [12,13]. Chemical and physical properties are greatly influenced by extractives, with characteristic colors and textures generating extensive market demand and heavy deforestation. Hence, these species are 
protected by Appendix II of CITES, D. cultrate is included in the list of national key preserved wild plants in the People's Republic of China (first batch). However, any species appearing in Appendix II of CITES are banned from international commercial trade except for those with an import and export license or re-export certificate [14]. Therefore, a more persuasive method for distinguishing closely related species is needed.

Traditional wood anatomy identification methods based on macroscopic and microscopic characteristics have been well-established for several years [15]. However, wood anatomy is too specialized for legal identification, especially when considering leaves, flowers, fruits, and other information to provide the extent of identification required by CITES [16]. By contrast, chemotaxonomical and genetic methods are useful in wood identification [17]. Previous investigations have found chemotaxonomical identification based on the analysis of extractive compounds to be an effective method for distinguishing extremely similar wood species [18-20].

To the best of our knowledge, Fourier transform infrared (FTIR) spectroscopy is a fast, simple, non-destructive method and a powerful technology to determine functional groups in the fingerprint region. This approach has been widely used in identification of complex systems such as traditional Chinese medicines and is suitable for analyzing woody materials [21,22]. In recent years, research on infrared spectroscopy in wood extractive studies has grown in popularity [23-25]. Additionally, gas chromatography-mass spectrometry (GC-MS) offers clear advantages when analyzing complex mixtures; the combination of an ideal separation technique (GC) with a sensitive identification technique (MS) constitutes a reliable and commonly used method for qualitative and quantitative analysis of compounds [26-28]. GC-MS has been widely applied in establishing chromatographic fingerprints for quality evaluation of herbal medicines [29]. It has also been well-established in the characterization and identification of wood extractive compounds [30-32].

Little research has been carried out to identify the three similar Dalbergia species Dalbergia cultrate, Dalbergia latifolia, and Dalbergia melanoxylon based on chemical taxonomy. This paper examines differences in extractive contents and components using FTIR and GC-MS approaches to discriminate chemotaxonomically between the extractive components in Dalbergia spp. Functional group analysis using FTIR spectroscopy and detailed analysis of their components by GC-MS allow one to classify similar species by their chemical nature. These two techniques also facilitate comprehensive analysis of chemical components to support the chemotaxonomical classification of wood. GC-MS data provide a persuasive basis for specific compounds identified by infrared absorption spectra, as the two methods are complementary and valuable in chemotaxonomical identification.

\section{Results and Discussion}

\subsection{Contents Analysis of Extractives}

The extractive contents of the three Dalbergia species are listed in Table 1. Dalbergia cultrate, Dalbergia latifolia, and Dalbergia melanoxylon were extracted with four different polar organic solvents, the extractive contents were calculated, and the average value of three experiments was taken. The findings indicated that the non-polar solvent $n$-hexane was not suitable for wood extraction, indicating that the extractable components of these three kinds of wood are mostly polar. After successfully extracting samples with ethanol/water, benzene/ethanol, ethyl acetate respectively, the extract contents were clearly different. Among the benzyl alcohol and ethyl acetate extracts of the three species Dalbergia cultrate had the lowest content, whereas the content of Dalbergia melanoxylon was highest. With ethanol/water $(9: 1, v / v)$, the content of Dalbergia cultrate was slightly higher than that in Dalbergia latifolia but clearly lower than in Dalbergia melanoxylon. Therefore, Dalbergia melanoxylon contained more types of main compounds than Dalbergia cultrate, and Dalbergia latifolia had the fewest kinds of principle compounds, likely because it contained fewer polar components. In general, the effect of ethanol/water $(9: 1, v / v)$ was better than benzyl alcohol and ethyl acetate, and more components could be obtained. Therefore, to analyze the primary extractive 
components in Dalbergia cultrate, Dalbergia latifolia, and Dalbergia melanoxylon, ethanol/water (9:1, v/v) was used as the final solvent in this experiment.

Table 1. Comparison of extractive contents in different solvents.

\begin{tabular}{ccccc}
\hline \multirow{2}{*}{ Species } & \multicolumn{4}{c}{ Yield of Extractives (\%) } \\
\cline { 2 - 5 } & $\begin{array}{c}\text { Ethanol/Water } \\
\mathbf{( 9 : 1 , ~} \mathbf{v / v )}\end{array}$ & $\begin{array}{c}\text { Benzene/Ethanol } \\
(\mathbf{2 : 1 ,} \boldsymbol{v} / \boldsymbol{v})\end{array}$ & Ethyl Acetate & n-Hexane \\
\hline Dalbergia cultrate & 11.6 & 8.6 & 6.2 & - \\
Dalbergia latifolia & 10.1 & 9.65 & 6.8 & - \\
Dalbergia melanoxylon & 16.65 & 16.05 & 13.0 & - \\
\hline
\end{tabular}

\subsection{FTIR Analysis}

The FTIR spectra of the Dalbergia cultrate, Dalbergia latifolia, and Dalbergia melanoxylon extractives are illustrated in Figure 1. Detailed peak positions are summarized in Table 2. The characteristic infrared absorption peaks of the functional groups of the main extractive components were reflected in the FTIR spectra. In the region of $3401-2839 \mathrm{~cm}^{-1}$, all spectra exhibited strong, broad peaks attributable to the stretching vibration of $\mathrm{O}-\mathrm{H}$ or N-H along with a moderate-intensity peak ascribed to methyl and methylene stretching vibrations. Benzene ring characteristic peaks (1602,1510, and $1450 \mathrm{~cm}^{-1}$ ) of the three species were clear and strong, indicating a large proportion of aromatic substances [33]. However, the relative intensity of these three peaks was distinctly different. Especially for Dalbergia cultrate, the intensity of peaks at $1602 \mathrm{~cm}^{-1}$ and $1445 \mathrm{~cm}^{-1}$ was stronger, suggesting that the number, location, and properties of substituents on aromatic rings varied between the three species. Moreover, Dalbergia cultrate showed strong absorption bands around $1691 \mathrm{~cm}^{-1}$ for $\mathrm{C}=\mathrm{O}$, a peak around $1555 \mathrm{~cm}^{-1}$ with medium intensity for $\mathrm{C}=\mathrm{C}$ of the aromatic ring, and strong absorption peaks at $1286 \mathrm{~cm}^{-1}$ and $1153 \mathrm{~cm}^{-1}$ for C-O-C [34]; these findings were presumably due to skeletal stretching vibration of the aromatic rings $\mathrm{A}$ and $\mathrm{B}$ and the functional group $\mathrm{C}-\mathrm{O}-\mathrm{C}$ of ring $\mathrm{C}$ of flavonoids $[24,35]$. These peaks were clearly visible only in Dalbergia cultrate; the $\mathrm{C}=\mathrm{O}$ was weak for Dalbergia melanoxylon and was essentially invisible for Dalbergia latifolia, indicating an abundance of flavonoid compounds in Dalbergia cultrate.

Dalbergia cultrate also generated a stronger sharp absorption peak at $1378 \mathrm{~cm}^{-1}$. In general, methyl groups have two absorption peaks around $1375 \mathrm{~cm}^{-1}$ and $1450 \mathrm{~cm}^{-1}$, corresponding to symmetric bending vibrations and asymmetric bending vibrations, respectively [36]; this finding explains why the peak strength of Dalbergia cultrate at $1445 \mathrm{~cm}^{-1}$ was so strong. Then, the absorption peaks at $1366 \mathrm{~cm}^{-1}$ of Dalbergia melanoxylon and $1352 \mathrm{~cm}^{-1}$ of Dalbergia latifolia were ascribed to either $\mathrm{CH}_{3}$ symmetrical bending or in-plane $\mathrm{C}-\mathrm{OH}$ bending, as the spectral band shape was low and wide.

Peaks in the region ranging from $910 \mathrm{~cm}^{-1}$ to $1300 \mathrm{~cm}^{-1}$ were mainly due to C-O single bond stretching vibrations. The extractives of the three species exhibited clear, strong peaks at $1200 \mathrm{~cm}^{-1}$ primarily due to C-O-C stretching; however, the band intensity of the three species included typical vibrations around $1270 \mathrm{~cm}^{-1}$ (Ar-O) and $1023 \mathrm{~cm}^{-1}$ (R-O) for C-O vibrations, although the peak intensity at $1270 \mathrm{~cm}^{-1}$ in Dalbergia melanoxylon was stronger than that in Dalbergia latifolia. Dalbergia melanoxylon likely contained more aromatic ether functional groups; a peak appeared at $1130 \mathrm{~cm}^{-1}$ for $\mathrm{C}-\mathrm{OH}$ stretching of the alcohol groups [36]. C-OH stretching near $1114 \mathrm{~cm}^{-1}$ was found exclusively in Dalbergia cultrate. A C-H out-of-plane bending peak was seen around $999 \mathrm{~cm}^{-1}$ in the spectrum of Dalbergia cultrate and around $917 \mathrm{~cm}^{-1}$ in the spectrum of Dalbergia latifolia. Unique vibrations near $700 \mathrm{~cm}^{-1}$ were ascribed to the stretching vibration of C-S, which was obvious in Dalbergia cultrate and Dalbergia latifolia. 


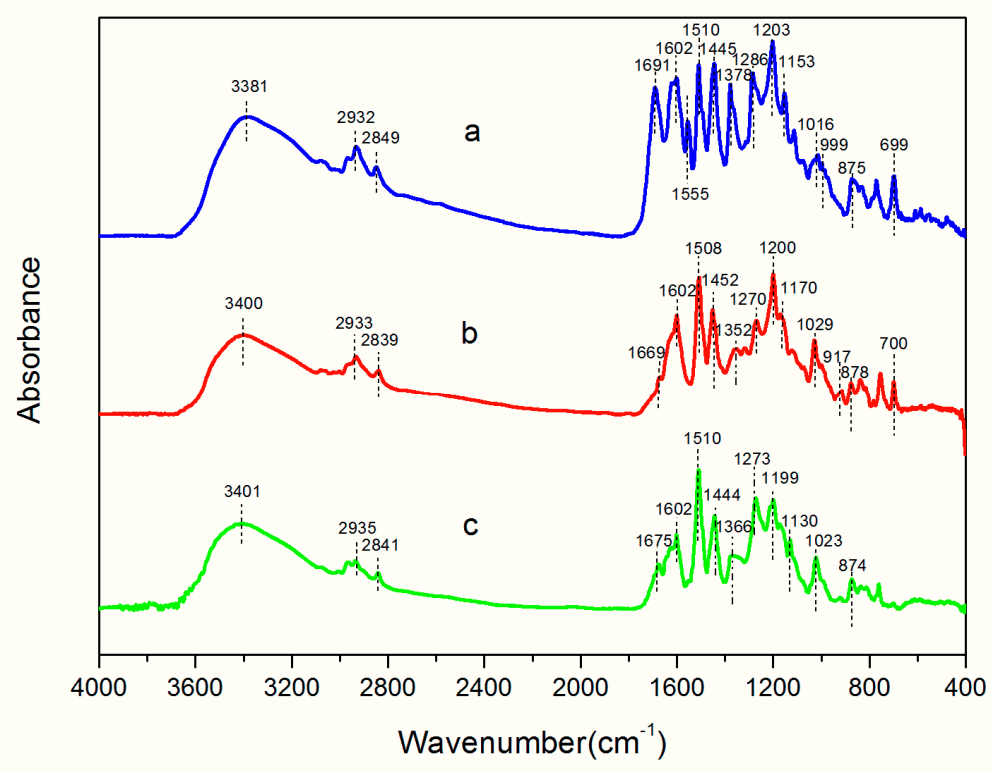

Figure 1. FTIR spectra: (a) D. cultrate, (b) D. latifolia, (c) D. melanoxylon.

Table 2. FTIR band assignment.

\begin{tabular}{|c|c|c|c|}
\hline \multicolumn{3}{|c|}{ Wavenumbers $\left(\mathrm{cm}^{-1}\right)$} & \multirow[b]{2}{*}{ Band Assignments } \\
\hline D. Cultrata & D. Latifolia & D. Melanoxylon & \\
\hline 3381 & 3400 & 3401 & O-H stretch; $\mathrm{N}-\mathrm{H}$ stretch \\
\hline 2932 & 2933 & 2935 & $\mathrm{C}-\mathrm{H}$ stretch: $\mathrm{CH}_{2}$ \\
\hline 2849 & 2839 & 2841 & C-H stretch: $\mathrm{CH}_{3}$ \\
\hline 1691 & 1669 & 1675 & $\mathrm{C}=\mathrm{O}$ stretch; $\mathrm{C}=\mathrm{N}$ stretch \\
\hline 1602 & 1602 & 1602 & $\mathrm{C}=\mathrm{C}$ stretching of aromatic skeleton \\
\hline 1555 & - & - & $\mathrm{C}=\mathrm{C}$ stretching of aromatic skeleton \\
\hline 1510 & 1508 & 1510 & C-C stretch bands within ring skeleton \\
\hline- & 1452 & - & $\begin{array}{c}\text { Skeletal C-C stretching; } \mathrm{CH}_{3} \text { symmetrical bending } \\
\text { vibrations } ; \mathrm{CH}_{2} \text { scissoring }\end{array}$ \\
\hline 1445 & & 1444 & $\begin{array}{c}\text { Aromatic stretching(flavonoids); } \mathrm{CH}_{3} \text { symmetrical bending } \\
\text { vibrations }\end{array}$ \\
\hline 1378 & - & - & $\mathrm{CH}_{3}$ asymmetrical bending vibrations \\
\hline & & 1366 & $\begin{array}{l}\mathrm{CH}_{3} \text { symmetrical bending; in-plane } \mathrm{C}-\mathrm{OH} \text { bending } \\
\text { rical bending }\end{array}$ \\
\hline- & 1352 & & $\begin{array}{l}\mathrm{CH}_{3} \text { symmetrical bending; in-plane } \mathrm{C}-\mathrm{OH} \text { bending } \\
\mathrm{C}-\mathrm{N}-\mathrm{C} \text { asymmrtric vibration of aromatic compounds }\end{array}$ \\
\hline- & 1318 & - & in-plane $\mathrm{C}-\mathrm{OH}$ bending; C-O stretching \\
\hline 1286 & - & - & C-O-C stretching (flavonoids) \\
\hline- & 1270 & 1273 & C-O vibration \\
\hline 1203 & 1200 & 1199 & C-O-C stretching \\
\hline- & 1170 & - & $\begin{array}{c}\text { C-O stretching } \\
\text { C-O-C stretching or frame vibration (flavonoids) }\end{array}$ \\
\hline 1153 & - & - & $\begin{array}{l}\text { C-O-C stretching(flavonoids); in-plane C-OH bending } \\
\text { C-O-C stretching or frame vibration (flavonoids) }\end{array}$ \\
\hline - & - & 1130 & $\mathrm{C}-\mathrm{OH}$ stretching \\
\hline 1114 & - & - & $\mathrm{C}-\mathrm{OH}$ stretching \\
\hline 1016 & 1029 & 1023 & C-O stretching \\
\hline 999 & - & - & $\begin{array}{l}\text { C-H out-of-plane bend } \\
\text { C-O stretching }\end{array}$ \\
\hline- & 917 & - & C-H out-of-plane bend \\
\hline 875 & 878 & 874 & C-O stretching \\
\hline- & 839 & 836 & $\mathrm{C}-\mathrm{H}$ stretching out of plane of aromatic ring; $\mathrm{C}-\mathrm{N}$ wagging \\
\hline 699 & 700 & & $\mathrm{C}-\mathrm{H}$ stretching out of plane of aromatic ring; C-S stretching \\
\hline
\end{tabular}




\subsection{GC-MS Analysis}

The GC-MS chromatograms of Dalbergia cultrata, Dalbergia latifolia, and Dalbergia melanoxylon extractives are presented in Figure 2. The results show clearly the different characteristic peaks of the three species. The peak area was chosen as the analytical signal for the relative amount. The relative content of each chemical component was calculated by area normalization and the average value of the three experiments. Identified chemical components (peak area above 1.0\%) and the relative content of these compounds are listed in Table 3. The main chemical components of the three species were determined to be aromatic compounds. In general, these compounds were classified into flavonoids, miscellaneous, quinones, phenols, esters, stilbenoids, and amide compounds. The components of the extracts of Dalbergia cultrata, Dalbergia latifolia, and Dalbergia melanoxylon are detailed below.

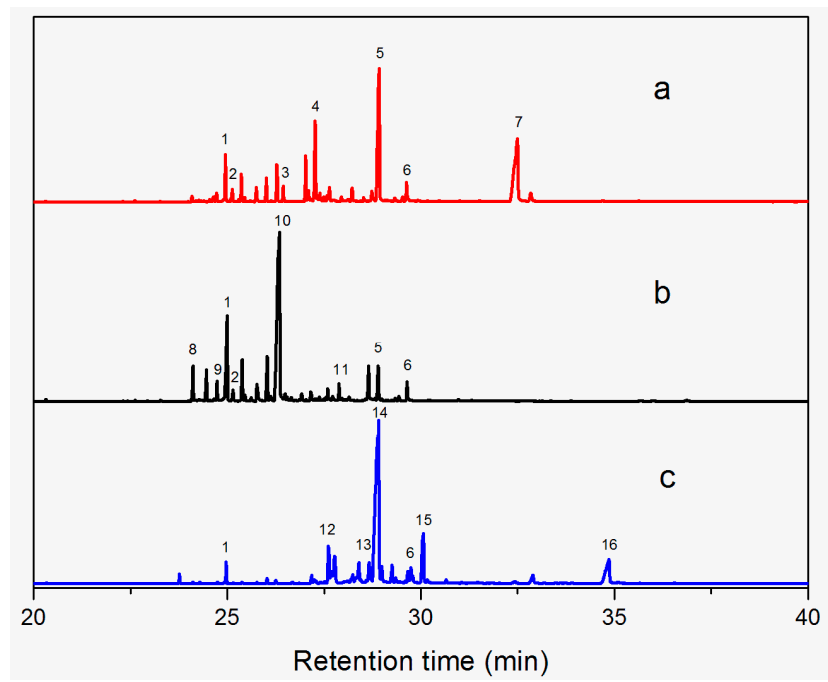

Figure 2. Total ion chromatogram: (a) D. cultrate, (b) D. latifolia, (c) D. melanoxylon.

Table 3 reveals there were only two common compounds among the three species and each species also contained unique chemical components. The following three compounds were specific to Dalbergia cultrata: 3,3',4,4'-tetramethoxystilbene (peak 3, 1.49\%), $3,7,3^{\prime}, 4^{\prime}$-tetrahydroxyflavone (peak $4,10.78 \%$ ), and parietin (peak $7,24.81 \%$ ). Particular compounds found exclusively in Dalbergia latifolia included the following: 1,7,7-trimethyl-3-phenethylidenebicyclo[2.2.1] heptan-2-one (peak 8, 3.28\%), 4,4'-methylenebis-2,6-dimethylphenol (peak 9, 1.60\%), 4,2', $3^{\prime}, 4^{\prime}$-tetramethoxy-5'-methyl-6-methylaminomethyl-1,1'-biphenyl (peak 10, 29.75\%), (4-methyl- sulfanylphenyl)carbamic acid 2,6-dimethoxyphenyl ester (peak 11, 1.38\%). GC-MS analysis of Dalbergia melanoxylon revealed five distinct compounds: 10,11-dihydro-10-hydroxy2,3-dimethoxydibenz(b,f)oxepin (peak 12, 4.57\%), 2-(4-methoxy-2,5-dimethylphenyl)-9-methyl-2Hbenzo[g]indazole (peak 13, 3.14\%), 10,11-dihydro-10-hydroxy-2,3,6-trimethoxydibenz(b,f)oxepin (peak 14, 37.30\%), 10,11-dihydro-2,3,6-trimethoxydibenz(b,f)oxepin-10-one (peak 15, 8.32\%), and pilloin (peak $16,7.77 \%$ ).

According to the GC-MS analysis results, the principal components of the three species varied. Seven constituents were identified as having higher relative contents in Dalbergia cultrate: 3,7,3' ${ }^{\prime} 4^{\prime}$-tetrahydroxyflavone (peak 4, 10.78\%), 7-methoxy-1-thioflavone (peak 5, 25.55\%), and parietin (peak 7, 24.81\%). 7-Methoxy-1-thioflavone is a flavonoid derivative. Some thioflavones have been reported to function as novel neuroprotective agents and exhibit antiviral activities. $3,7,3^{\prime}, 4^{\prime}$-Tetrahydroxyflavone is a natural flavonol in foods and plants and has been identified as showing various biological activities. Parietin is an anthroquinone and has been identified in the traditional Chinese herbal medicines Polygoni multiflora and Eryngium foetidum L. 
Table 3. Chemical composition of extractives analyzed by GC/MS.

\begin{tabular}{|c|c|c|c|c|c|c|}
\hline \multirow{2}{*}{ ID } & \multirow{2}{*}{ RT(min) } & \multirow{2}{*}{ Compounds } & \multirow{2}{*}{ Molecular Structure } & \multicolumn{3}{|c|}{ Releative Content (\%) * } \\
\hline & & & & D. Cultrate & D. Latifolia & D. Melanoxylon \\
\hline 1 & 24.97 & Phenol,4-methyl-2-[5-(2-thienyl)pyrazol-3-yl]- & & 4.76 & $12.41(0.7)$ & 1.47 \\
\hline 6 & 29.66 & 13-Docosenamide, $(Z)$ - & & $2.08(0.2)$ & $2.17(0.2)$ & $1.26(0.1)$ \\
\hline 2 & 25.13 & Naphtho[2,3-b]furan-4,9-dione, 2-isopropyl- & & 1.54 & $1.36(0.2)$ & - \\
\hline 5 & 28.90 & 1-Thioflavone, 7-methoxy- & & $25.55(0.2)$ & 4.23 & - \\
\hline 3 & 26.44 & $3,3^{\prime}, 4,4^{\prime}$-Tetramethoxystilbene & & 1.49 & - & - \\
\hline 4 & 27.26 & $3,7,3^{\prime}, 4^{\prime}$-Tetrahydroxyflavone & & $10.78(0.1)$ & - & - \\
\hline 7 & 32.49 & Parietin & & $24.81(0.4)$ & - & - \\
\hline 8 & 24.11 & $\begin{array}{c}\text { 1,7,7-Trimethyl-3- } \\
\text { phenethylidenebicyclo[2.2.1]heptan-2-one }\end{array}$ & & - & 3.28 & - \\
\hline 9 & 24.73 & Phenol, 4,4'-methylenebis[2,6-dimethyl- & & - & 1.60 & - \\
\hline 10 & 26.32 & $\begin{array}{l}\text { 1,1'-Biphenyl, } 4,2^{\prime}, 3^{\prime}, 4^{\prime} \text {-tetramethoxy- } \\
\text { 5'-methyl-6-methylaminomethyl- }\end{array}$ & & - & $29.75(0.8)$ & - \\
\hline
\end{tabular}


Table 3. Cont

\begin{tabular}{|c|c|c|c|c|c|c|}
\hline \multirow{2}{*}{ ID } & \multirow{2}{*}{$\mathrm{RT}(\mathrm{min})$} & \multirow{2}{*}{ Compounds } & \multirow{2}{*}{ Molecular Structure } & \multicolumn{3}{|c|}{ Releative Content (\%) * } \\
\hline & & & & D. Cultrate & D. Latifolia & D. Melanoxylon \\
\hline 11 & 27.88 & $\begin{array}{l}\text { (4-Methylsulfanylphenyl)carbamic acid, } \\
\text { 2,6-dimethoxyphenyl ester }\end{array}$ & & - & 1.38 & - \\
\hline 12 & 27.76 & $\begin{array}{l}\text { 10,11-Dihydro-10-hydroxy-2,3- } \\
\text { dimethoxydibenz(b,f)oxepin }\end{array}$ & & - & - & 4.57 \\
\hline 13 & 28.66 & $\begin{array}{l}\text { 2-(4-Methoxy-2,5-dimethyl-phenyl)-9- } \\
\text { methyl-2H-benzo[g]indazole }\end{array}$ & & - & - & 3.14 \\
\hline 14 & 28.88 & $\begin{array}{l}\text { 10,11-Dihydro-10-hydroxy-2,3, } \\
\text { 6-trimethoxydibenz(b,f)oxepin }\end{array}$ & & - & - & $37.30(0.8)$ \\
\hline 15 & 30.06 & $\begin{array}{l}\text { 10,11-Dihydro-2,3,6- } \\
\text { trimethoxydibenz(b,f)oxepin-10-one }\end{array}$ & & - & - & $8.32(0.2)$ \\
\hline 16 & 34.86 & Pilloin & & - & - & $7.77(0.1)$ \\
\hline
\end{tabular}

* The percentage was calculated based on the peak area. Values in the parentheses are the deviations of three replicates. Deviations lower than $0.1 \%$ are not listed in the table. 
Analysis also revealed the presence of eight compounds in Dalbergia latifoli with 4-methyl2-[5-(2-thienyl)pyrazol-3-yl]phenol (peak 1, 12.41\%) and 4,2', 3', $4^{\prime}$-tetramethoxy-5'-methyl-6-methylaminomethyl-1,1'-biphenyl (peak 10, 29.75\%) being the most predominant. Both compounds were previously identified in Dalbergia Stevenson based on GC-MS results [25,37]. Seven components were recognized in Dalbergia melanoxylon, with larger proportions of 10,11-dihydro-10-hydroxy-2,3,6-trimethoxydibenz(b,f)oxepin (peak 12, 37.30\%), 10,11-dihydro2,3,6-trimethoxydibenz(b,f)oxepin-10-one (peak 14, 8.32\%), and pilloin (peak 16, 7.77\%). 10,11-Dihydro-10-hydroxy-2,3,6-trimethoxydibenz(b,f)oxepin was previously identified in Dalbergia Stevenson [19,37]. Pilloin is a flavonoid extracted from the Ovidia pillo-pillo plant, Marrubium cylleneum, and propolis.

\section{Materials and Methods}

\subsection{Wood Samples}

The Latin names, trade names, and places of origin of the Dalbergia species are presented in Table 4. The three Dalbergia heartwood samples were obtained from the Research Institute of Wood Industry at the Chinese Academy of Forestry, China. Figure 3 shows tangential sections of the three kinds of Dalbergia heartwood. Three replicates were analyzed per sample.

Table 4. Latin and trade names and places of origin of investigated Dalbergia species.

\begin{tabular}{ccc}
\hline Latin Name & Trade Name & Place of Origin \\
\hline Dalbergia cultrate Benth. & Burmese blackwood & Laos \\
Dalbergia latifolia Roxb. & Indian rosewood & Indonesia \\
Dalbergia melanoxylon (Guill. \& Perr.) & African blackwood & Mozambique \\
\hline
\end{tabular}

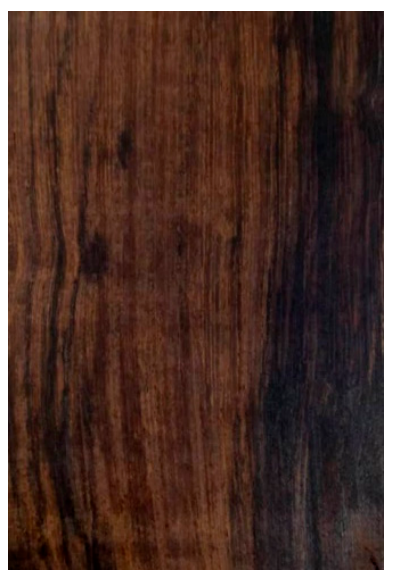

(a)

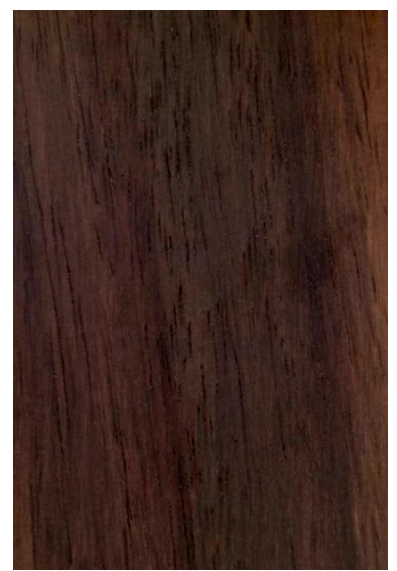

(b)

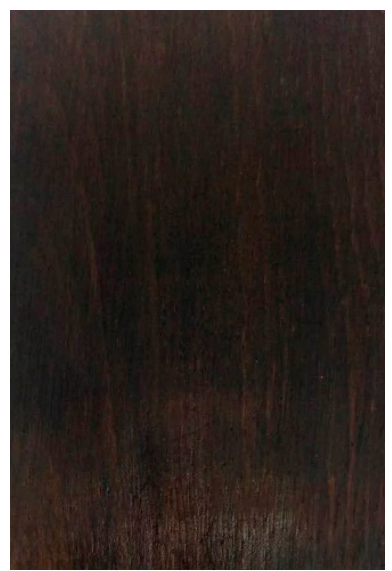

(c)

Figure 3. Heartwood of (a) Dalbergia cultrate, (b) Dalbergia latifolia and (c) Dalbergia melanoxylon.

\subsection{Preparation of Wood Extracts}

Heartwoods were chopped into thin pieces, air-dried, and finely powdered using an electric grinder (Baijie, Hangzhou, China). Then, 40-60 mesh powders $(0.2 \mathrm{~g})$ were extracted in ethanol/water $(10 \mathrm{~mL}, 9: 1, v / v)$, benzene/ethanol $(2: 1, v / v)$, and ethyl acetate in an ultrasonic bath for $1 \mathrm{~h}$ at room temperature. Ethanol (99.8\% purity), benzene (99.7\% purity), ethyl acetate (99.0\% purity), $n$-hexane (98.0\% purity) were purchased from Aladdin (Shanghai, China). Next, the mixture was centrifuged for $5 \mathrm{~min}$ and filtered through a $0.45-\mu \mathrm{m}$ pore size filter before the extraction solvent was dried in an oven at $103 \pm 2{ }^{\circ} \mathrm{C}$ to reach a consistent weight for further analysis. 


\subsection{FTIR Analysis}

Two mg of the $90 \%$ ethanol extract were mixed with $100 \mathrm{mg}$ of $\mathrm{KBr}$ powder in a smooth agate mortar. Then, the mixture was ground and pressed into a transparent pellet. FTIR spectra were obtained within a scanning range of $4000-400 \mathrm{~cm}^{-1}$ at a resolution of $4 \mathrm{~cm}^{-1}$ and 16 total scans using a Spectrum ONE spectrometer (Perkin Elmer, Waltham, MA, USA) equipped with a DTGS detector at room temperature. The instrument was free of $\mathrm{H}_{2} \mathrm{O}$ and $\mathrm{CO}_{2}$.

\subsection{GC-MS Analysis}

GC/MS analysis was carried out by a triple quadrupole GC-MS system 450GC-320MS, (Bruker Billerica, MA, USA). Separation was achieved using a DB-5MS column $(30 \mathrm{~m} \times 0.25 \mathrm{~mm} \times$ $0.25 \mu \mathrm{m}$; Agilent Technologies, Santa Clara, CA, USA $)$ with a temperature program from $50{ }^{\circ} \mathrm{C}(5 \mathrm{~min})$ to $290{ }^{\circ} \mathrm{C}(12 \mathrm{~min})$ at $10{ }^{\circ} \mathrm{C} / \mathrm{min}$ with helium as the carrier gas $(1 \mathrm{~mL} / \mathrm{min})$. The solvent was delayed $4.5 \mathrm{~min}$; the injection volume was $1 \mu \mathrm{L}$ at a split ratio of 10 . The mass spectrometer was operated in electron impact mode $(70 \mathrm{eV})$, and masses were scanned over a range of $40-800 \mathrm{~m} / \mathrm{z}$. The transmission line temperature was $250{ }^{\circ} \mathrm{C}$, and the ion source temperature was $200{ }^{\circ} \mathrm{C}$. Peak assignment was accomplished by comparing the MS spectra to the National Institute of Standards and Technology (NIST 2010) library.

\section{Conclusions}

This study reveals that Dalbergia cultrate, Dalbergia latifolia, and Dalbergia melanoxylon can be successfully distinguished based on extractive analysis. Initially, the extract content of the three species was found to be different, with Dalbergia melanoxylon demonstrating the highest extractive content. By comparing different solvents, the extraction components were found to be mostly polar. Then, FTIR spectra effectively revealed additional information about the functional groups of the extractive components. We also identified the unique and primary components using GC-MS. The main chemical components of the three species varied, and 7-methoxy-1-thioflavone, $4,2^{\prime}, 3^{\prime}, 4^{\prime}$ tetramethoxy-5'-methyl-6-methylaminomethyl-1,1'-biphenyl and 10,11-dihydro-10-hydroxy-2,3,6trimethoxydibenz $(\mathrm{b}, \mathrm{f})$ oxepin exhibited the highest relative content of the three species, respectively. Furthermore, each species contained its own characteristic components, a useful finding for distinguishing between the three species. In summary Dalbergia cultrate, Dalbergia latifolia, and Dalbergia melanoxylon can be distinguished successfully according to differences in extractive content, functional groups, and chemical composition.

Author Contributions: X.Y. performed the experiments, analyzed the data, and wrote the manuscript; A.H. conceived and designed the experiments; S.Z. reviewed the manuscript; R.L. and F.M. contributed to the analysis tools.

Funding: This work was supported by the National Natural Science Foundation of China (No. 31670564).

Conflicts of Interest: The authors declare no conflict of interest.

\section{References}

1. Hillis, W.E. Heartwood and Tree Exudates; Springer: Berlin, Germany, 1987; pp. 76-119.

2. Roffael, E. Significance of wood extractives for wood bonding. Appl. Microbiol. Biotechnol. 2015, 100, 1589-1596. [CrossRef] [PubMed]

3. Hillis, W.E. Distribution, properties, and formation of some wood extractives. Wood Sci. Technol. 1971, 5, 272-289. [CrossRef]

4. Schultz, T.P.; Nicholas, D.D. Naturally durable heartwood evidence for a proposed dual defensive function of the extractives. Phytochemistry 2000, 54, 47-52. [CrossRef]

5. Umezawa, T. Chemistry of extractives. In Wood and Cellulosic Chemistry; Taylor Francis Inc.: New York, NY, USA, 2000. 
6. Tittikpina, N.K.; Nana, F.; Fontanay, S.; Philippot, S.; Batawila, K.; Akpagana, K. Antibacterial activity and cytotoxicity of pterocarpus erinaceus poir extracts, fractions and isolated compounds. J. Ethnopharmacol. 2018, 212, 200-207. [CrossRef] [PubMed]

7. Nagawa, C.B.; Böhmdorfer, S.; Rosenau, T. Chemical composition of volatiles extracted from indigenous tree species of Uganda: Composition of bark extracts from Psorospermum febrifugum and Milicia excelsa. Holzforschung 2015, 69, 815-821. [CrossRef]

8. Seshadri, T.R. Polyphenols of Pterocarpus and Dalbergia woods. Phytochemistry 1972, 11, 881-898. [CrossRef]

9. Convention on International Trade in Endangered Species of Wild Fauna and Flora. Appendices I, II, and III; Government of South Africa: Johannesburg, South Africa, 24 September 2016.

10. Li, Q.; Wu, J.; Wang, Y.; Lian, X.; Wu, F.; Zhou, L. The phylogenetic analysis of Dalbergia (fabaceae: Papilionaceae) based on different DNA barcodes. Holzforschung 2017, 71, 939-949. [CrossRef]

11. Jenkins, M.; Oldfield, S.; Aylett, T.; Jenkins, M.; Oldfield, S.; Aylett, T. International Trade in African Blackwood; Fauna and Flora International: Cambridge, UK, 2002.

12. Barrett, M.A.; Brown, J.L.; Morikawa, M.K.; Labat, J.; Yoder, A.D. CITES Designation for endangered rosewood in Madagascar. Science 2010, 328, 1109-1110. [CrossRef] [PubMed]

13. Hassold, S.; Ii, P.P.L.; Bauert, M.R.; Razafintsalama, A.; Ramamonjisoa, L.; Widmer, A. DNA barcoding of malagasy rosewoods: Towards a molecular identification of cites-listed Dalbergia species. PLoS ONE 2016, 11. [CrossRef] [PubMed]

14. APPENDIX. A Summary of the Criteria for the Three CITES Appendices. Available online: https://www. cites.org (accessed on 8 May 2018).

15. Richter, H.G.; Krause, V.J.; Muche, C. Wood Structure and physico-chemical properties compared with other central American species of Dalbergia. IAWA J. 1996, 17, 327-341. [CrossRef]

16. Gasson, P.; Miller, R.; Stekel, D.J.; Whinder, F.; Zieminska, K. Wood identification of Dalbergia nigra (Cites Appendix I) using quantitative wood anatomy, principal components analysis and nacve bayes classification. Ann. Bot. 2010, 10545-10546.

17. Wu, C.C.; Chu, F.H.; Ho, C.K.; Sung, C.H.; Chang, S.H. Comparative analysis of the complete chloroplast genomic sequence and chemical components of cinnamomum micranthum and cinnamomum kanehirae. Holzforschung 2017, 71, 189-197. [CrossRef]

18. Kite, G.C.; Green, P.W.C.; Veitch, N.C.; Groves, M.C.; Gasson, P.E.; Simmonds, M.S.J. Dalnigrin, a neoflavonoid marker for the identification of brazilian rosewood (Dalbergia nigra) in cites enforcement. Phytochemistry 2010, 71, 1122-1131. [CrossRef] [PubMed]

19. Wang, S.; Zhang, F.; Huang, A.; Zhou, Q. Distinction of four Dalbergia species by FTIR, 2nd derivative IR, and 2D-IR spectroscopy of their ethanol-benzene extractives. Holzforschung 2016, 70, 503-510. [CrossRef]

20. Vidaković, V.; Novaković, M.; Popović, Z.; Janković, M.; Matić, R.; Tešević, V. Significance of diarylheptanoids for chemotaxonomical distinguishing between Alnus glutinosa and Alnus incana. Holzforschung 2017, 72, 9-16. [CrossRef]

21. Huang, A.; Zhou, Q.; Liu, J.; Fei, B.; Sun, S. Distinction of three wood species by Fourier transform infrared spectroscopy and two-dimensional correlation IR spectroscopy. J. Mol. Struct. 2008, 883, 160-166. [CrossRef]

22. Ma, F.; Huang, A. Rapid identification and quantification three chicken-wing woods of Millettia leucantha, Millettia laurentii and Cassia siamea by FT-IR and 2DCOS-IR. J. Mol. Struct. 2018, 1166, 164-168. [CrossRef]

23. Luo, S.; Wu, Y.; Huang, J. Thermal and Chemical Properties of Benzene/Alcohol Extractives from Two Species of Redwood. In Proceedings of the 2012 International Conference on Biobase Material Science and Engineering (BMSE), Changsha, China, 21-23 October 2012; pp. 156-160.

24. Zhang, F.; Xu, C.; Li, M.; Chen, X.; Zhou, Q.; Huang, A. Identification of Dalbergia cochinchinensis (cites appendix ii) from other three Dalbergia, species using $\mathrm{ft}$-ir and $2 \mathrm{~d}$ correlation ir spectroscopy. Wood Sci. Technol. 2016, 50, 693-704. [CrossRef]

25. Wang, F.; Huang, A.; Yin, X.; Wang, W.; Chen, J. Multilevel profiling and identification of Dalbergia odorifera and Dalbergia stevensonii by FTIR, NMR and GC/MS. Chin. Chem. Lett. 2017, 29, 1395-1398. [CrossRef]

26. Iordache, A.; Culea, M.; Gherman, C. Characterization of some plant extracts by GC-MS. Nucl. Instrum. Methods Phys. Res. B 2009, 267, 338-342. [CrossRef]

27. Mangindaan, B.; Matsushita, Y.; Aoki, D.; Yagami, S.; Kawamura, F.; Fukushima, K. Analysis of distribution of wood extractives in gmelina arborea by gas chromatography and time-of-flight secondary ion mass spectrometry. Holzforschung 2017, 71, 299-305. [CrossRef] 
28. Liu, R.; Wang, C.; Huang, A.; Lv, B. Characterization of Odors of Wood by Gas Chromatography-Olfactometry with Removal of Extractives as Attempt to Control Indoor Air Quality. Molecules 2018, 23, 203. [CrossRef] [PubMed]

29. Pan, R.; Guo, F.; Lu, H.; Feng, W.; Liang, Y. Development of the chromatographic fingerprint of scutellaria barbata D. Don by GC-MS combined with chemometrics methods. J. Pharm. Biomed. Anal. 2011, 55, 391-396. [CrossRef] [PubMed]

30. Fernandez, M.P.; Watson, P.A.; Breuil, C. Gas chromatography-mass spectrometry method for the simultaneous determination of wood extractive compounds in quaking aspen. J. Chromatogr. A 2001, 922, 225-233. [CrossRef]

31. Vaysi, R. Identification and comparison of chemical components in wood and bark of planted eldar pine tree by GC/MS methods. Pro Ligno 2014, 10, 21-25.

32. Xu, B.; Zhu, T.; Li, J.; Liu, S. Identification of wood between Phoebe zhennan and Machilus pingii using the gas chromatography-mass spectrometry direct injection technique. Eur. J. Mass Spectrom. 2013, 19, 187-193. [CrossRef]

33. Zhang, Z.; Li, H.; Sun, S.; Huang, L.; Noda, I. Differentiation of Rhizoma Curcumas longae and Radix Curcumae by a multistep infrared macro-fingerprint method. Anal. Lett. 2013, 46, 2597-2609. [CrossRef]

34. Xu, R.; Sun, S.; Zhu, W. Multi-step infrared macro-fingerprint features of ethanol extracts from different Cistanche species in China combined with HPLC fingerprint. J. Mol. Struct. 2014, 1069, 236-244. [CrossRef]

35. Liu, Y.; Li, J.; Fan, G.; Sun, S.; Zhang, Y.; Zhang, Y. Identification of the traditional tibetan medicine "shaji" and their different extracts through tri-step infrared spectroscopy. J. Mol. Struct. 2016, 1124, 180-187. [CrossRef]

36. Sun, S.; Zhou, Q.; Chen, J. Infrared Spectroscopy for Complex. Mixtures: Applications in Food and Traditional Chinese Medicine; Chemical Industry Press: Beijing, China, 2011; pp. 58-61.

37. Jiang, S.; Ge, S.; Wang, M.; Peng, W. Molecules and functions of rosewood: Dalbergia stevenson. Arab. J. Chem. 2017. [CrossRef]

Sample Availability: Samples of the compounds are not available from the authors.

(C) 2018 by the authors. Licensee MDPI, Basel, Switzerland. This article is an open access article distributed under the terms and conditions of the Creative Commons Attribution (CC BY) license (http://creativecommons.org/licenses/by/4.0/). 